\title{
Antitumor effects and molecular mechanisms of action of natural products in ovarian cancer (Review)
}

\author{
YUN-BO YAN $^{1 *}$, QING TIAN ${ }^{1,2^{*}}$, JI-FANG ZHANG $^{1 *}$ and YING XIANG ${ }^{1,2}$ \\ ${ }^{1}$ Laboratory of Oncology, Center for Molecular Medicine, School of Basic Medicine, Health Science Center, Yangtze \\ University; ${ }^{2}$ Department of Cell Biology and Genetics, School of Basic Medicine, Health Science Center, \\ Yangtze University, Jingzhou, Hubei 434023, P.R. China
}

Received November 28, 2019; Accepted August 3, 2020

DOI: $10.3892 / \mathrm{ol} .2020 .12001$

\begin{abstract}
Ovarian cancer is a common malignancy and the second leading cause of mortality among females with genital tract cancer. At present, postoperative platinum drugs and paclitaxel-based chemotherapy is the gold standard treatment for ovarian cancer. However, patients who receive this chemotherapy often develop cumulative toxic effects and are prone to chemotherapy resistance. Therefore, it is necessary to determine more effective treatment options that would be better tolerated by patients. Recent studies have reported the
\end{abstract}

Correspondence to: Dr Ying Xiang, Department of Cell Biology and Genetics, School of Basic Medicine, Health Science Center, Yangtze University, 1 Nanhuan Road, Jingzhou, Hubei 434023, P.R. China

E-mail: xying316@163.com

${ }^{*}$ Contributed equally

Abbreviations: EGCG, (-)-Epigallocatechin-3-gallate; PI3K, phosphatidylinositol 3-kinase; Akt, protein kinase B; Bcl-2, B-cell lymphoma-2; STAT-3, signal transducer and activator of transcription-3; IL, interleukin; SERCA, sarcoplasmic/endoplasmic reticulum $\mathrm{Ca}^{+}$ transporting ATPase; miR, miRNA; LC3, microtubule-associated protein 1 light chain 3; mTOR, mammalian target of rapamycin; ER, endoplasmic reticulum; EMT, epithelial-to-mesenchymal transition; MMPs, matrix metalloproteinases; FAK, focal adhesion kinase; uPA, urokinase plasminogen activator; VCAM-1, vascular cell adhesion molecule-1; MDR-1, multidrug resistance protein 1; PTEN, phosphatase and tensin homolog; GSK3 $\beta$, glycogen synthase kinase-3 $\beta$; VEGF, vascular endothelial growth factor; ERK, extracellular signal-regulating kinase; ARHI, aplasia Ras homologue member I; AMPK, AMP-activated protein kinase; HIF-1 $\alpha$, hypoxia-inducible factor-1 $\alpha$; MAPK, mitogen-activated protein kinase; TRAIL, tumor necrosis factor-related apoptosis inducing ligand; PGE2, prostaglandin E2; hERG1, human ether a-go-go related potassium channel; PDCD4, programmed cell death-4; CTR1, copper transporter 1; hTERT, human telomerase reverse transcriptase; PARP, poly ADP-ribose polymerase

Key words: ovarian cancer, natural products, molecular mechanisms, antitumor therapeutic effects of numerous natural products in patients with ovarian cancer. Notably, these natural ingredients do not induce adverse effects in healthy cells and tissues, suggesting that natural products may serve as a safe alternative treatment for ovarian cancer. The antitumor effects of natural products are attributed to suppression of cell proliferation and metastasis, stimulation of autophagy, improved chemotherapy sensitivity, and induction of apoptosis. The present review focused on the antitumor effects of several natural products, including curcumin, resveratrol, ginsenosides, (-)-epigallocatechin-3-gallate and quercetin, which are increasingly being investigated as therapeutic options in ovarian cancer, and discussed the molecular mechanisms involved in cell proliferation, apoptosis, autophagy, metastasis and sensitization.

\section{Contents}

1. Introduction

2. Curcumin

3. Resveratrol

4. Ginsenosides

5. Quercetin

6. Berberine

7. (-)-Epigallocatechin-3-gallate

8. Conclusions and perspectives

\section{Introduction}

Ovarian cancer ranks third after cervical and uterine corpus cancer among gynecologic cancers and is the second leading cause of mortality worldwide among females with reproductive tract malignancies (1). Histopathologically, the majority of ovarian cancers are classified as epithelial ovarian cancer and include serous, mucinous, endometrioid, transitional and clear cell carcinomas (2). Epithelial ovarian cancer may metastasize through intracavitary implantation and/or the hematogenous and lymphatic routes. Intraperitoneal metastasis is the most common route of dissemination $(3,4)$. Patients are usually asymptomatic in the early stages of the disease and $\sim 70 \%$ of patients with ovarian cancer are diagnosed at an advanced stage (5). At present, surgery followed by platinum drugs and paclitaxel-based chemotherapy is the gold standard treatment to inhibit disease progression. However, patients who receive this chemotherapy often develop cumulative toxic effects 
(including nephrotoxicity) and are prone to chemotherapy resistance $(6,7)$. To date, ovarian cancer is associated with a poor prognosis (8); the 5-year survival rate of patients with this malignancy remains significantly low to be satisfactory in clinic. Therefore, newer drugs and novel treatment strategies are warranted to improve the prognosis of patients with ovarian cancer.

Owing to the high toxicity associated with conventional antitumor drugs, plant-derived natural products are being investigated as alternative or adjuvant treatments for a variety of cancer types (9). Conventionally, natural products are considered nutritional products and auxiliary medicine. Recent studies have proven the antitumor effects of natural products and demonstrated that they may reduce chemotherapy-induced toxicity. These phytochemicals primarily include curcumin, resveratrol, ginsenoside, quercetin, berberine and (-)-epigallocatechin-3-gallate (EGCG) (10). This review discusses the antitumor effects of several natural products and the molecular mechanisms of action of these agents in patients with ovarian cancer, with regards to their roles in proliferation, apoptosis, autophagy, metastasis and sensitization. The antitumor effects of several natural products and the molecular mechanism in ovarian cancer are reviewed, which includes the aspects of proliferation, apoptosis, autophagy, metastasis and sensitization.

\section{Curcumin}

Turmeric, the root of the Curcuma longa plant, is widely used in Indian curries and South Asian dishes, and has been used as a traditional medicine for thousands of years in India and China (11). Curcumin and its two related curcuminoids (demethoxycurcumin and bisdemethoxycurcumin) constitute the main active ingredients of turmeric. Reportedly, curcumin and curcuminoids possess strong antitumor, antioxidant, and anti-inflammatory properties owing to their interactions with multiple molecular targets (12). The antitumor effect and mechanisms of action of curcumin in ovarian cancer are listed in Table I.

Anti-proliferative and pro-apoptotic activity. Excessive proliferation and inadequate apoptosis are the two significant characteristics of tumors, including ovarian cancer. The phosphatidylinositol 3-kinase (PI3K)/protein kinase B (AKT) signaling pathway participates in multiple cellular process, and activation of this pathway increases cell proliferation, invasion, migration, survival and chemotherapy resistance in ovarian cancer (13). The B-cell lymphoma-2 (Bcl-2) family controls the release of cytochrome $\mathrm{C}$ from mitochondria into the cytosol, where it binds to apoptotic protease activating factor-1, promoting the activation of caspase- 9 then caspase-3, which leads to the intrinsic apoptosis. The Bcl-2 family includes the pro-apoptotic proteins (including $\mathrm{Bad}$ and Bax) and anti-apoptotic proteins (including Bcl-2, and Bcl-xl) (14). Curcumin downregulated the expression of the Bcl-2, while upregulating the expression of Bax and caspase-3 by repressing the PI3K/AKT pathway, leading to cell cycle arrest in $\mathrm{G} 2 / \mathrm{M}$ phase and increased apoptosis of ovarian cancer cells (15). Concordantly, Watson et al (16) reported that curcumin downregulated AKT phosphorylation, Bcl-2 and survivin, so that curcumin activated the extrinsic and intrinsic apoptotic pathways via activation of caspase-8, caspase-9 and caspase-3 (16). Signal transducer and activator of transcription-3 (STAT-3), is a transcription factor and signal transducer, and the phosphorylated STAT-3 promotes tumorigenesis by stimulating cell proliferation and preventing apoptosis (17). Saydmohammed et al (18), reported that curcumin inhibited STAT-3 phosphorylation, which suppressed ovarian cancer cell growth (18). Treatment with curcumin suppressed ovarian cell motility by inhibiting STAT-3 phosphorylation by increasing interleukin (IL)-6 and IL-8 secretion (19). In addition, $\mathrm{Ca}^{2+}$ homeostasis is necessary for cell survival, and sarcoplasmic/endoplasmic reticulum $\mathrm{Ca}^{2+}$ transporting ATPase (SERCA) regulates cellular $\mathrm{Ca}^{2+}$ flux from the cytosol to the endoplasmic reticulum (ER) for storage (20). Seo et al (21), reported that curcumin inhibited SERCA activity and then disrupted $\mathrm{Ca}^{2+}$ homeostasis in ovarian cancer cells. Subsequently, a high concentration of $\mathrm{Ca}^{2+}$ in the cytoplasm promoted cell apoptosis (21).

MiRNAs (miRs), a class of short non-coding RNAs, regulating gene expression post-transcriptionally via binding to the 3 '-untranslated regions of target mRNAs, are essential in malignant phenotype and treatment response in ovarian cancer (22). Du et al (23), reported that treatment with dimethoxy-curcumin promoted the apoptosis and inhibited the proliferation of ovarian cancer cells through upregulating the levels of miR-551a. A luciferase assay confirmed that miR-551a targeted insulin receptor substrate 2 (23), which had been validated to serve an anti-apoptotic role (24). In addition, it was demonstrated that the combination of dihydroartemisinin and curcumin arrested the cell cycle and promoted the apoptosis of ovarian cancer cells by upregulation of miR-124 and downregulation of its target midkine (25), which is significantly overexpressed in various cancer types to promote tumorigenesis and progression (26). Furthermore, curcumin promoted the apoptosis and inhibited the proliferation of ovarian cancer cells by inducing the expression of miR-9 (27).

Induction of autophagy. In ovarian cancer, autophagy serves a dual role that it may serve as an adaptation to stress to avoid cell death in cancer progression, while excessive autophagy may lead to cell death. Increased autophagy is also associated with resistance to chemotherapy (28). Autophagy is a highly conserved process that involves the formation of autophagosomes that engulf cellular proteins and organelles, and delivers them to the lysosomes. The mammalian target of the rapamycin (mTOR) signaling pathway regulates cell proliferation, survival and autophagy. The p70 ribosomal S6 protein kinase (p70S6K) is a major effector of mTOR phosphorylation (29). Liu et al (30), reported that curcumin inhibited the AKT/mTOR/p70S6K pathway to induce apoptosis and protective autophagy in ovarian cancer SKOV3 and A2780 cells, and treatment with autophagy-specific inhibitors markedly enhanced curcumin-induced apoptosis (30). Qu et al (31), reported that B19, a novel monocarbonyl analogue of curcumin, induced autophagy and ER stress-mediated apoptosis in ovarian cancer cells, and inhibition of autophagy with 3-methyladenine increased ER stress-mediated apoptosis (31). ER stress 


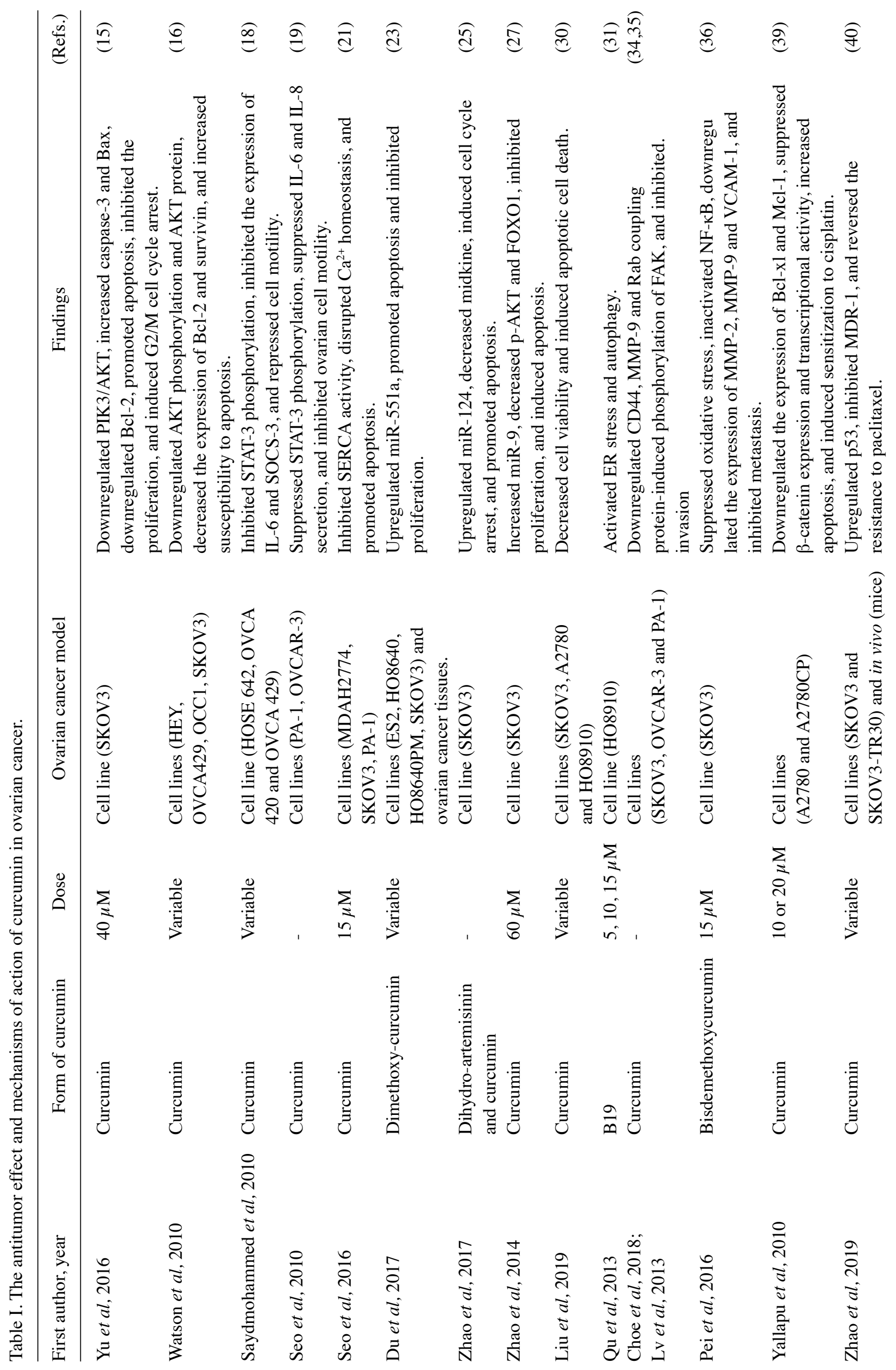


is referred to as the accumulation of unfolded or misfolded proteins in the ER lumen due to physiological and pathological conditions, which interfered with ER homeostasis and proper protein folding (32).

Anti-metastatic activity. Ovarian cancer metastasizes to adjacent organs via direct extension or through the dissemination of cancer cells that detach from the primary tumor (3). A family of proteolytic enzymes, called matrix metalloproteinases (MMPs), promote the metastasis of ovarian cancer by remodeling the tumor extracellular matrix (33). Two recent studies reported that curcumin markedly downregulated CD44 (the cell surface receptor of hyaluronic acid), MMP-9 and Rab coupling protein-induced phosphorylation of focal adhesion kinase (FAK; associated with the stabilization of actin and microtubule filaments, and regulating cancer cell motility), and eventually inhibited the invasion of SKOV3 cells $(34,35)$. In addition, one study revealed that bisdemethoxycurcumin inactivated the nuclear transcription factor-kappa $\mathrm{B}(\mathrm{NF}-\kappa \mathrm{B})$ pathway by inhibiting oxidative stress, thereby reducing the expression of metastasis-associated proteins, including MMP-2, MMP-9 and vascular cell adhesion molecule-1 (VCAM-1) in SKOV3 cells (36). The VCAM-1-integrin interaction was clarified to be involved in the regulation of ovarian cancer cell invasion and metastatic progression (37).

Sensitization. Resistance to chemotherapeutic agents is a major barrier to the effective treatment of advanced ovarian cancer. The molecular mechanisms associated with resistance to chemotherapy in ovarian cancer include increased activity of the drug efflux pump mediated by the multidrug resistance protein 1 (MDR-1, also known as P-gp), increased repair capacity of DNA damage, decreased drug intake, and decreased apoptosis, as well as drug-induced cell cycle arrest (38). Curcumin may increase the sensitivity of ovarian cancer cells to therapeutic drugs. Yallapu et al (39), reported that curcumin induced sensitization of cisplatin-resistant ovarian cancer cells (A2780CP) to cisplatin by increasing apoptosis. Curcumin treatment downregulated the expression of Mcl-1 and Bcl-xl, two anti-apoptotic proteins of the Bcl-2 family, and suppressed the activity of $\beta$-catenin, a transcription factor that promoted the expression of cell survival genes by interacting with the TCF transcription factor (39). Zhao et al (40), reported that co-administration of curcumin and paclitaxel exerted a good antitumor effect in multi-drug resistant ovarian cancer cells (SKOV3-TR30) and in ovarian tumor-bearing nude mice, since curcumin reversed the resistance to paclitaxel by inhibiting the drug efflux mediated by MDR-1 (40). Zhang et al (41) reported that curcumin may resume LncRNA MEG3 levels in extracellular vesicles from cisplatin-resistant ovarian cancer cells. Upregulation of MEG3 reduced the expression of miR-214 in cells and in extracellular vesicles, thereby reducing cisplatin resistance (41). MiR-214 was a well-known miRNA in drug resistance, which enhanced cell survival and induced cisplatin resistance in ovarian cancer cells by directly downregulating the expression of phosphatase and tensin homolog (PTEN), a negative regulatory molecule of the PI3K/AKT pathway (42). 


\section{Resveratrol}

Resveratrol is a natural polyphenolic compound derived from plants, including grapes, peanuts and Polygonum cuspidatum (43). Resveratrol possesses anti-inflammatory and antitumor properties, and protects the heart, nerves and kidneys (44). The antitumor effect and mechanisms of action of resveratrol in ovarian cancer are listed in Table II.

Anti-proliferative and pro-apoptotic activity. The Warburg effect describes that, under the condition of sufficient oxygen, tumor cells are active in aerobic glycolysis (45). Through aerobic glycolysis, a large number of metabolites may be generated and plentiful biosynthesis may occur, which may satisfy the rapid and unlimited growth of tumor cells (46). Suppression of the Warburg effect is an effective way to treat cancer (47). In the mouse model, resveratrol significantly reduced glucose uptake by tumor cells (48). In ovarian cancer cells, resveratrol inhibited the biosynthesis of hexosamine, and interrupted protein glycosylation through activating glycogen synthase kinase- $3 \beta$ (GSK3 $\beta$ ), and eventually triggered ER stress-mediated apoptosis (49). GSK3 $\beta$ is a kinase that phosphorylated and inactivated glycogen synthase, the final enzyme in biosynthesis of glycogen, which is the main form of glucose storage (50). Tino et al (51) proved that the combination of resveratrol and acetyl resveratrol inhibited the growth and metabolism of ovarian cancer cells more efficiently, and this growth restriction was due to decreased NF- $\mathrm{KB}$ protein and nuclear localization, which was responsible for vascular endothelial growth factor (VEGF) secretion (51). Furthermore, resveratrol downregulated the phosphorylation of AKT and GSK3 $\beta$ in a dose-dependent manner in ovarian cancer cells, as well as decreasing the activity of extracellular signal-regulating kinase (ERK), which subsequently suppressed the expression of cyclin D1, which facilitated cyclin-dependent kinases CDK4 or CDK6 in promoting cell cycle progression (52).

Induction of autophagy. In ovarian cancer, a recent study reported that resveratrol promoted autophagy and subsequent apoptosis in ovarian cancer cells by triggering the production of reactive oxygen species (53). Furthermore, it also revealed that resveratrol induced autophagy through enhancing the expression of Atg5, a key molecule for the elongation of the autophagosome membrane, and promoting cleavage from microtubule-associated protein 1 light chain 3 (LC3)-I to LC3-II (53). LC3-II, located on the membrane of autophagosomes, is a specific marker protein for autophagic activity (54). Beclin-1 mediates the localization of autophagy-related proteins and regulates the formation and maturation of autophagosomes by interacting with various proteins. Beclin-1 may also interact with the anti-apoptotic proteins of the Bcl-2 family, exerting a crosstalk between apoptosis and autophagy (55). Zhong et al (56) demonstrated that resveratrol enhanced autophagy by promoting the expression of beclin-1 and LC3-II through inactivation of STAT-3, and significantly induced growth arrest and death of ovarian cancer cells (56). In addition, resveratrol promoted the expression of the tumor suppressor gene, aplasia Ras homologue member I (ARHI) (57), and inactivated the STAT-3 signal pathway in ovarian cancer cells. Subsequently, resveratrol induced cell apoptosis, increased autophagy activity, and induced growth arrest (58). Concordantly, Ferraresi et al (59) reported that resveratrol increased autophagy via upregulation of beclin-1 and LC3 through induced ARHI and inactivated STAT-3, thereby attenuating the metastasis induced by IL- 6 in ovarian cancer cells (59). They also demonstrated that resveratrol inhibited mTOR complex 1 by repressing AKT and activating AMP-activated protein kinase (AMPK), which inhibited protein synthesis and cell growth, and induced autophagy. When the mTOR pathway was inhibited by resveratrol, induced autophagy favored the survival of cells in the context of insufficient nutrition, likely leading to a dormant state (60).

Anti-metastatic activity. Ovarian cancer is known to directly metastasize to the peritoneal surface of adjacent organs (3). A previous study demonstrated that resveratrol decreased the level of cellular $\alpha 5 \beta 1$ integrin and enhanced hyaluronic acid secretion to the extracellular matrix, which inhibited the adhesion of ovarian cancer cells to the intestinal wall and decreased metastasis (61). Under hypoxic conditions, resveratrol may decrease the binding between ovarian cancer cells and mesothelial cells by downregulating the expression of VEGF, thereby preventing the migration of ovarian cancer cells induced by lysophosphatidic acid (62). The high expression of VEGF was associated with metastasis in advanced ovarian cancer (63).

Sensitization. A previous study has reported that resveratrol induces autophagy and promotes apoptosis in ovarian cancer cells (64). Therefore, resveratrol may improve chemosensitivity and prevent tumorigenesis under conditions of autophagy inhibitors (64). Aberrant activation of NF- $\kappa \mathrm{B}$ may protect cancer cells against the apoptosis induced by pharmacological drugs, contributing toward drug resistance. Nessa et al (65) suggested that resveratrol sensitized ovarian cancer cells to the apoptosis induced by platinum drugs via downregulating NF-kB (65). In addition, Engelke et al (66) reported that resveratrol reversed the resistance of ovarian cancer cells to cisplatin by modulating molecular targets, including the EGFR or VEGFR family of receptor tyrosine kinases (66).

\section{Ginsenosides}

Ginsenosides constitute the major pharmacologically active ingredient in ginseng, and possess antitumor and antioxidant properties. In addition to enhancing immunity (67). Several ginsenoside compounds, including Rb1, Rg1, RG1, Rh1 and $\mathrm{Rd}$, have been identified, and the majority of these, particularly ginsenoside $\mathrm{Rg} 3$ and $\mathrm{Rb} 1$ exhibit significant antitumor activity (68). The effect and mechanisms of action of ginsenosides in ovarian cancer are list in Table III.

Anti-proliferative and pro-apoptotic activity. The Warburg effect is essential for tumor growth and metabolism. Li et al (69) reported that ginsenoside 20(S)-Rg3 downregulated phospho-STAT-3 and two metabolic enzymes, hexokinase and pyruvate kinase, which inhibited the glycolysis of ovarian cancer cells, thereby inhibiting the Warburg effect and preventing tumor growth and metabolism (69). A previous study reported that $20(\mathrm{~S})-\operatorname{Rg} 3$ may block the 


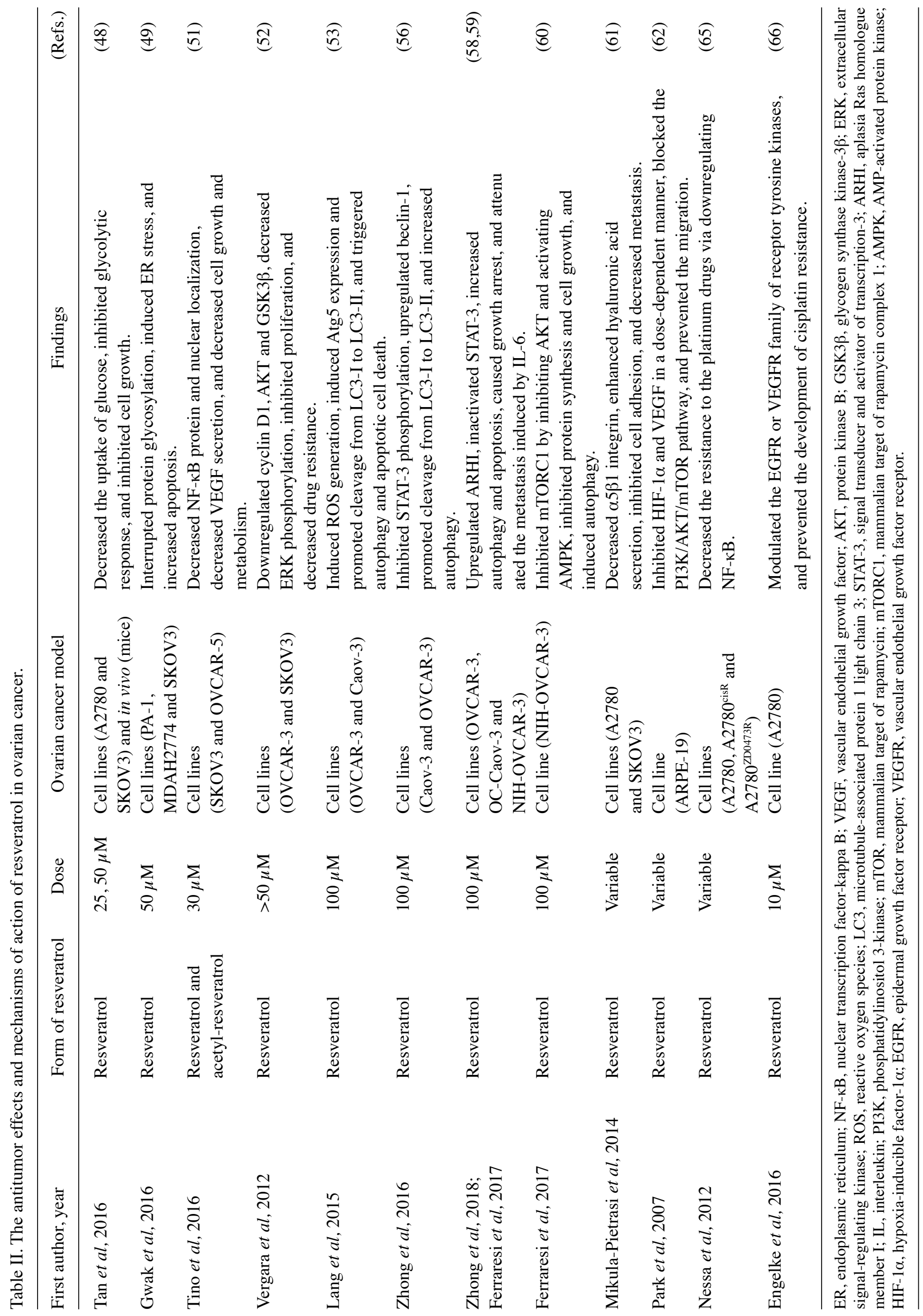




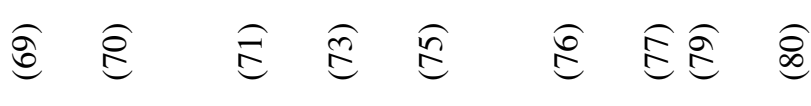

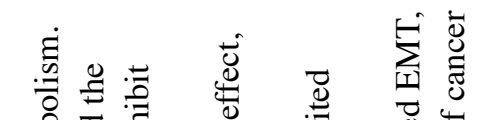

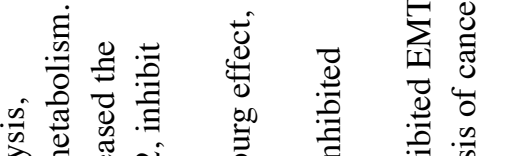

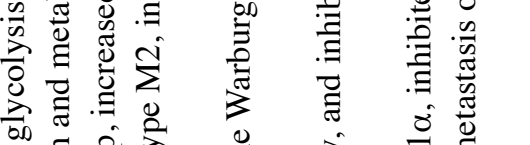

$\Xi$ की

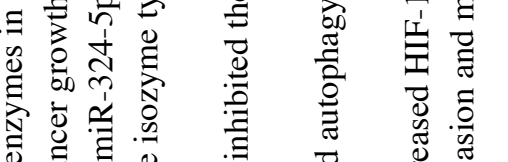

$\because$ ฮี

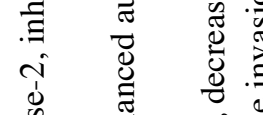

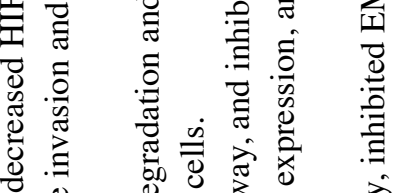

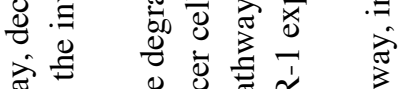

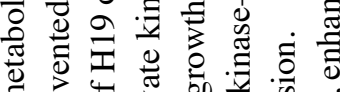

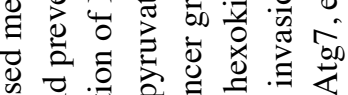

焉焉

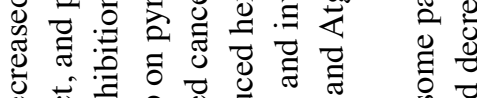

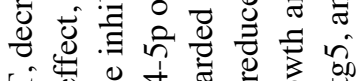

के

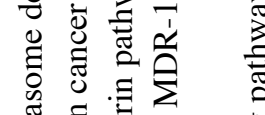

总

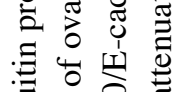

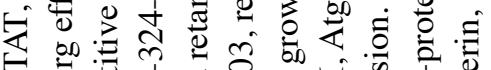

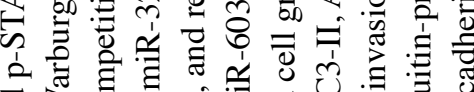

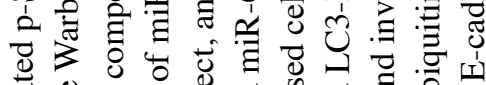

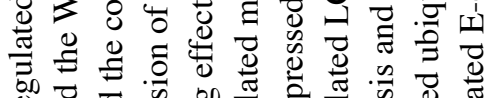

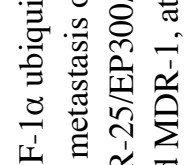

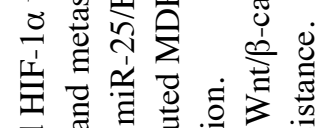

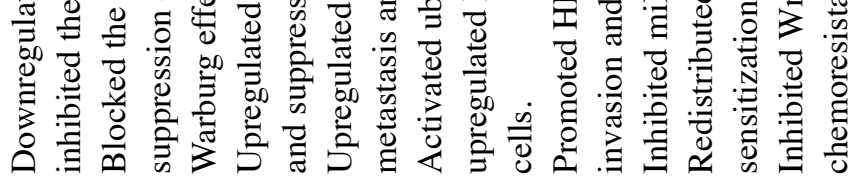

$\widehat{0} . \widehat{0}$

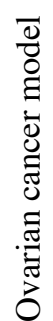

$\ddot{\infty}$

$4 \frac{\mathscr{\theta}}{0}$

हี

(1)

政

$\frac{n_{0}}{\frac{m}{1}}$

ठृ ڤ્त

离

¿े

.

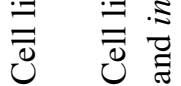

$\stackrel{\overbrace{}}{\stackrel{0}{ง}}$

๙

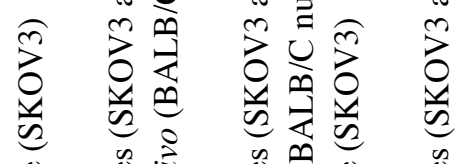

电包

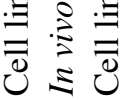

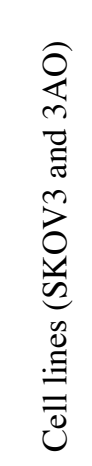

迹

च

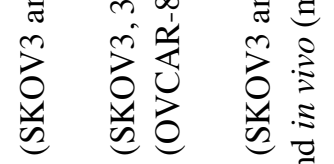

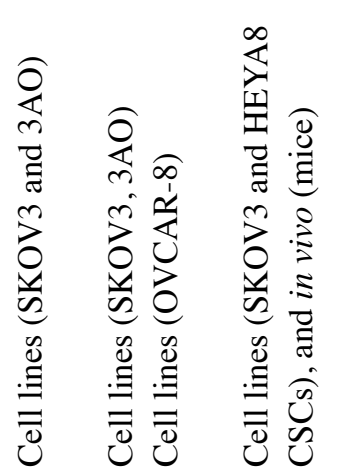

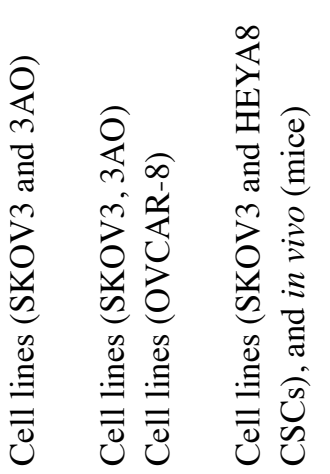

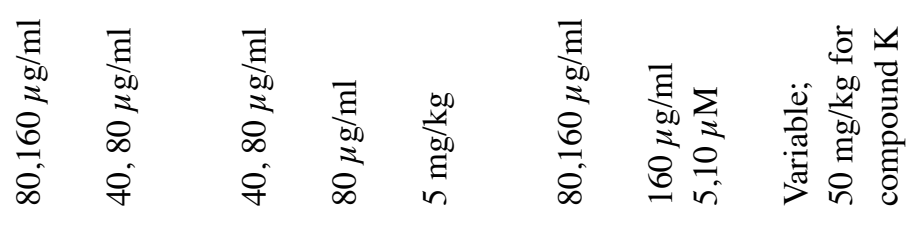

.

$\Xi$.

ธี

를

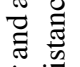

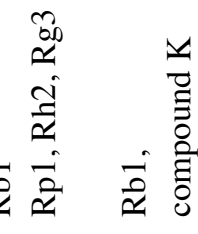

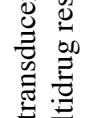

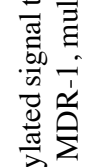

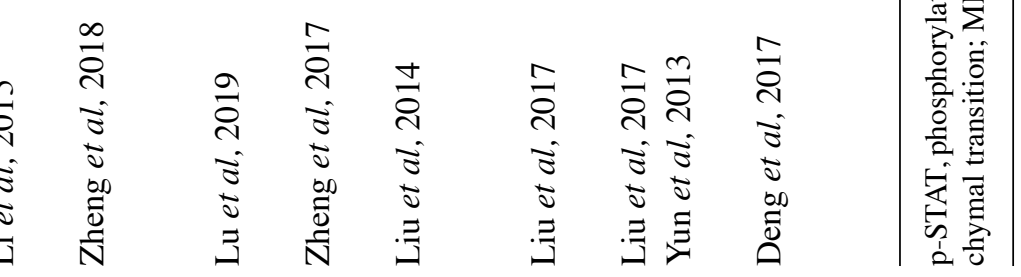


inhibition of miR-324-5p by H19. Increased miR-324-5p by 20(S)-Rg3 treatment inhibited the activity of pyruvate kinase isozyme type M2, thereby inhibiting the Warburg effect (70). Furthermore, Lu et al (71) reported that ginsenoside 20(S)-Rg3 upregulated the expression of miR-603 in ovarian cancer cells by downregulating the DNA methylation mediated by DNA methyltransferase 3 alpha. Increased miR-603 directly targeted hexokinase- 2 mRNA and decreased hexokinase-2 expression. Therefore, ginsenoside 20(S)-Rg3 inhibited the Warburg effect, which was primarily manifested as a decreased lactate production, glucose consumption and in vitro proliferation, and weakened cell invasion and migration (71).

Autophagy induction. The effect of ginsenosides on autophagy is controversial. Reportedly, ginsenoside 20(S)-Rg3 inhibited autophagic flux by suppression of late-stage autophagosome maturation or degradation, and eventually induced apoptosis in cervical cancer cells (72). However, in ovarian cancer, ginsenoside 20(S)-Rg3 enhanced autophagy by upregulating autophagy-related molecules, including LC3-II, Atg5 and Atg7, thereby inhibiting the invasion and metastasis of ovarian cancer cells (73).

Anti-metastatic activity. Hypoxia-inducible factor-1 (HIF-1), ubiquitous in human and mammalian cells, is stable only under hypoxic conditions, and the stabilization of HIF-1 $\alpha$ mediates tumor cell invasion and metastasis (74). The epithelial-to-mesenchymal transition (EMT) usually occurs prior to ovarian cancer metastasis, which decreases cell-cell adhesion. Liu et al (75) reported that ginsenoside 20(S)-Rg3 decreased the expression of HIF-1 $\alpha$ by stimulating the ubiquitin-proteasome pathway, and inhibited EMT process, which was essential for metastasis (75). They also revealed that ginsenoside 20(S)-Rg3 upregulated prolyl hydroxylase domain protein 1 to cause degradation of HIF-1 $\alpha$ under the conditions of normal oxygen (76). Furthermore, ginsenoside Rb1 inhibited hypoxia-induced EMT by downregulating miR-25 in ovarian cancer cells, which abrogated the suppression of miR-25 on the expression of EP300 (a transcriptional activator of E-cadherin) and E-cadherin (an essential molecule for adhesion between epithelial cells), thereby leading to an anti-metastatic effect (77). E-cadherin is involved in anchoring epithelial cells to each other by binding to the actin microfilaments through $\alpha$ - and $\beta$-catenin in the cytoplasm (78).

Sensitization. Drug resistance is a major clinical challenge that interferes with successful cancer therapy. The membrane transporter MDR-1 is located on the lipid rafts of the plasma membrane, and increased MDR-1 activity is an important contributor to multidrug resistance. Yun et al (79) reported that ginsenoside Rp1 repressed MDR-1 activity by redistributing lipid rafts, which reversed resistance to antitumor drugs, including doxorubicin (79). EMT is involved in drug resistance, as well as in metastasis. Deng et al (80) reported that the metabolite compound $\mathrm{k}$ of ginsenoside $\mathrm{Rb} 1$ specifically inhibited cell growth by inhibiting the $\mathrm{Wnt} / \beta$-catenin signaling pathway and EMT process, and decreased the resistance of ovarian cancer stem cells to cisplatin and paclitaxel (80).

\section{Quercetin}

Quercetin is a natural polyphenolic compound abundantly present in fruits and vegetables; notably, red onions contain the highest levels of quercetin (81). Quercetin has a variety of pharmacological actions, including antitumor, antioxidant and anti-inflammatory activity, in addition to lowering blood pressure and blood lipid levels. Quercetin-induced cytotoxicity is rarely observed in healthy cells (82). The antitumor effects and mechanisms of action of quercetin in ovarian cancer are listed in Table IV.

Anti-proliferative, pro-apoptotic and anti-metastatic activity. Quercetin exerts antitumor effects in vitro and in vivo (83). It was reported that quercetin inhibited the expression of survivin protein, and maintained the cell cycle at the G0/G1 stage, thereby inhibiting the proliferation and promoting the apoptosis of ovarian cancer cells (84). In addition, quercetin upregulated the expression of miR-145, and then activated caspase-8, caspase- 9 and caspase- 3 , which induced the apoptosis of ovarian cancer cells (85). In line with this, Teekaraman et al (86) reported that quercetin induced the intrinsic apoptosis in ovarian cancer cells. This study revealed that quercetin decreased the expression of anti-apoptotic proteins, Bcl-2 and Bcl-xl, while increasing the expression of the pro-apoptotic proteins, Bax and Bad, leading to the activation of caspase-9 and caspase-3 (86). In addition, Liu et al (87) reported that quercetin induced apoptosis and protective autophagy through ER stress, and the phospho-STAT-3/Bcl-2 signaling pathway was involved in this pharmacologic action (87). With regards to the role of quercetin in anti-metastasis, one study revealed that 3,4'7-O-trimethylquercetin inhibited the invasion and metastasis of ovarian cancer cells by decreasing the expression of MMP-2 and urokinase plasminogen activator (uPA) (88). MMP-2 was reported as an early regulator of metastasis, and uPA was reported to promote metastasis in ovarian cancer cells (88). However, the role of quercetin in autophagy in ovarian cancer remains unknown.

Sensitization. Several studies have investigated the combined treatment of quercetin and chemotherapy or radiotherapy in ovarian cancer, due to the sensitization function of quercetin. Wang et al (89), reported that quercetin aglycone induced caspase- 3 activation and poly-ADP-ribose polymerase (PARP; a DNA repair enzyme) deactivation, which caused cell apoptosis and promoted the sensitivity of ovarian cancer cells to cisplatin. Furthermore, quercetin inactivated the pro-survival mitogen-activated protein kinase (MAPK)-ERK signal pathway, downregulated cyclin D1 expression, and upregulated p21 expression, thereby arresting cell cycle progression (89). Yang et al (90) reported that quercetin increased the sensitivity of ovarian cancer cells to cisplatin by inducing ER stress. Furthermore, this study reported that quercetin significantly inhibited STAT-3 phosphorylation, and then downregulated Bcl-2 expression, attenuating the anti-apoptotic effect of Bcl-2 (90). In line with this, Gong et al (91) reported that quercetin enhanced the sensitivity to radiotherapy by the aggravation of DNA damage and ER stress through activating p53, which led to increased $\mathrm{p} 21$ and Bax expression, and decreased Bcl-2 expression (91). In addition, Yi et al (92) 


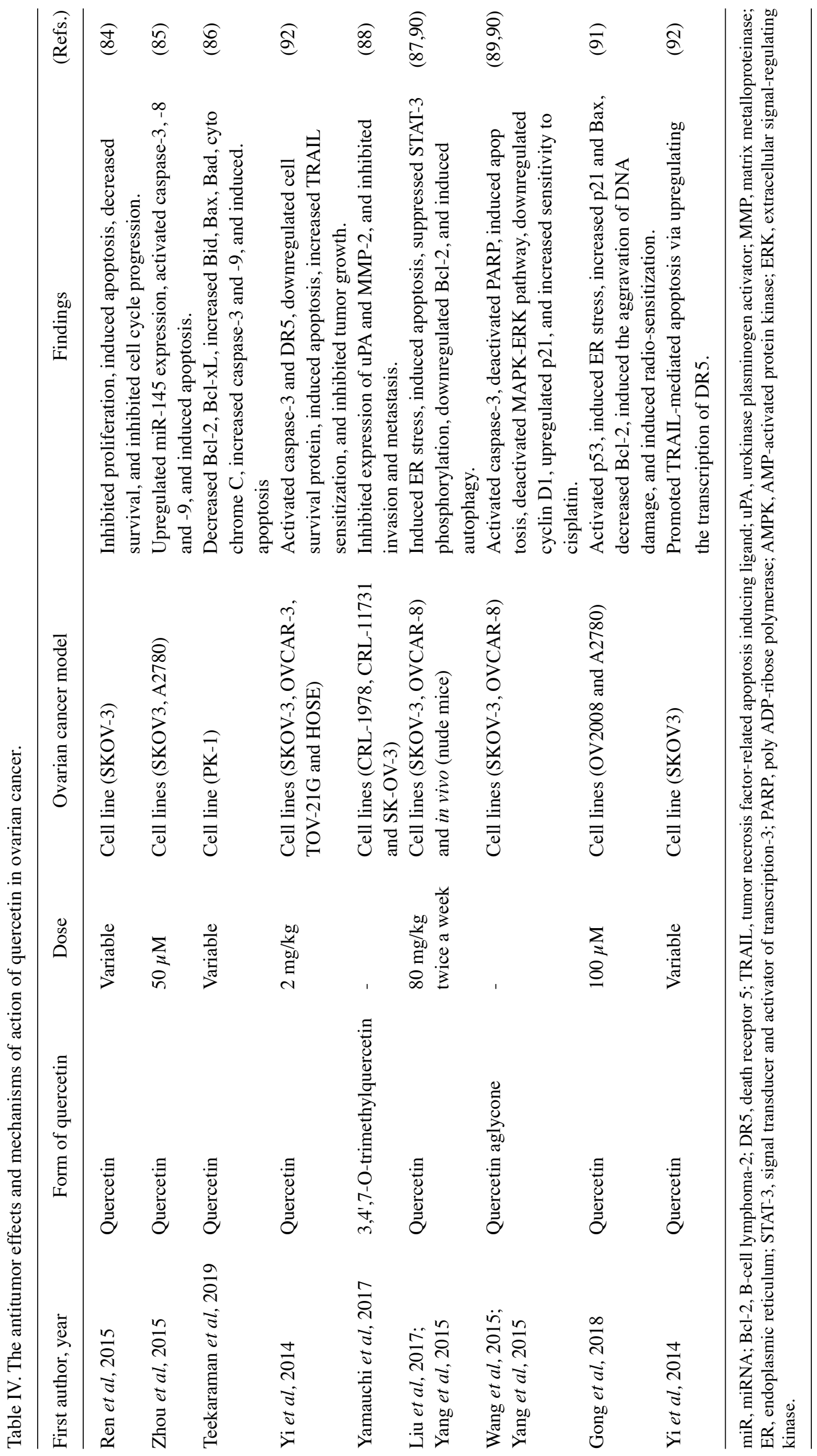


verified that quercetin increased the sensitivity of SKOV3 cells to tumor necrosis factor-related apoptosis inducing ligand (TRAIL)-mediated apoptosis by upregulating the transcription of death receptor 5 (DR5), the receptor of TRAIL (92). A high expression of DR5 was associated with a poor prognosis in patients with ovarian cancer (93).

\section{Berberine}

Berberine, an isoquinoline alkaloid, is the main bioactive ingredient of Coptis chinensis. Its pharmacological activity includes anti-inflammatory, antioxidant and antitumor effects (94). The antitumor effects and mechanisms of action of berberine in ovarian cancer are listed in Table V.

Anti-proliferative and pro-apoptotic activity. A previous study revealed that berberine inhibited the proliferation of tumor cells, and induced apoptosis and cell cycle arrest (95). Berberine alone or combined with cisplatin may induce ovarian cancer cells to arrest at the G0/G1 phase and enhance the activity of cell death-associated proteins, including caspase- 8 and caspase- 3 , thereby promoting apoptosis and necrosis (96). Prostaglandin E2 (PGE2) is a bioactive lipid that promotes cell proliferation and tumor growth (97). The chemotherapy drug VP16 promoted the synthesis of $\mathrm{PGE}_{2}$ by increasing the free arachidonic acid in ovarian cancer, which led to the proliferation of surrounding non-apoptotic cells and tumor repopulation. However, berberine inhibited the two key enzymes (calcium-independent phospholipase A2 and cyclooxygenase-2) of $\mathrm{PEG}_{2}$ synthesis in the tumor microenvironment, which resulted in decreased synthesis of $\mathrm{PEG}_{2}$ and inhibited the phosphorylation of FAK, which inhibited the chemotherapy-induced repopulation (98). Furthermore, berberine served an antitumor role in ovarian cancer by inhibiting the expression of the human ether a-go-go-related potassium channel (hERG1). The hERG1 protein was considered to be a key factor in tumorigenesis, and its high expression level in ovarian cancer cells may be downregulated by berberine treatment (99).

Autophagy induction and anti-metastatic activity. To date, the role of berberine in autophagy induction and the inhibition of ovarian cancer metastasis remains unclear. However, with regards to other cancer types, berberine was reported to induce autophagy and exhibited anti-metastatic action. Berberine was demonstrated to inhibit the MAPK/mTOR/p70S6K and Akt pathways in gastric cancer cells, thereby inducing cytostatic autophagy and cancer cell cycle arrest (100). Berberine may inhibit cell migration by downregulating matrix metalloproteinase-3 (MMP-3) in gastric carcinoma cells, thereby exhibiting anti-metastatic activity (101). In addition, berberine inhibited the metastasis of endometrial cells by downregulating the expression of cyclooxygenase-2 (102).

Sensitization. Marverti et al (103) reported the effect of berberine on sensitization in ovarian cancer. Berberine inhibited the growth of cisplatin-resistant ovarian cancer cells through suppressing the expression of dihydrofolate reductase and thymidylate synthase, two enzymes that are essential for DNA biosynthesis and thus important targets for 


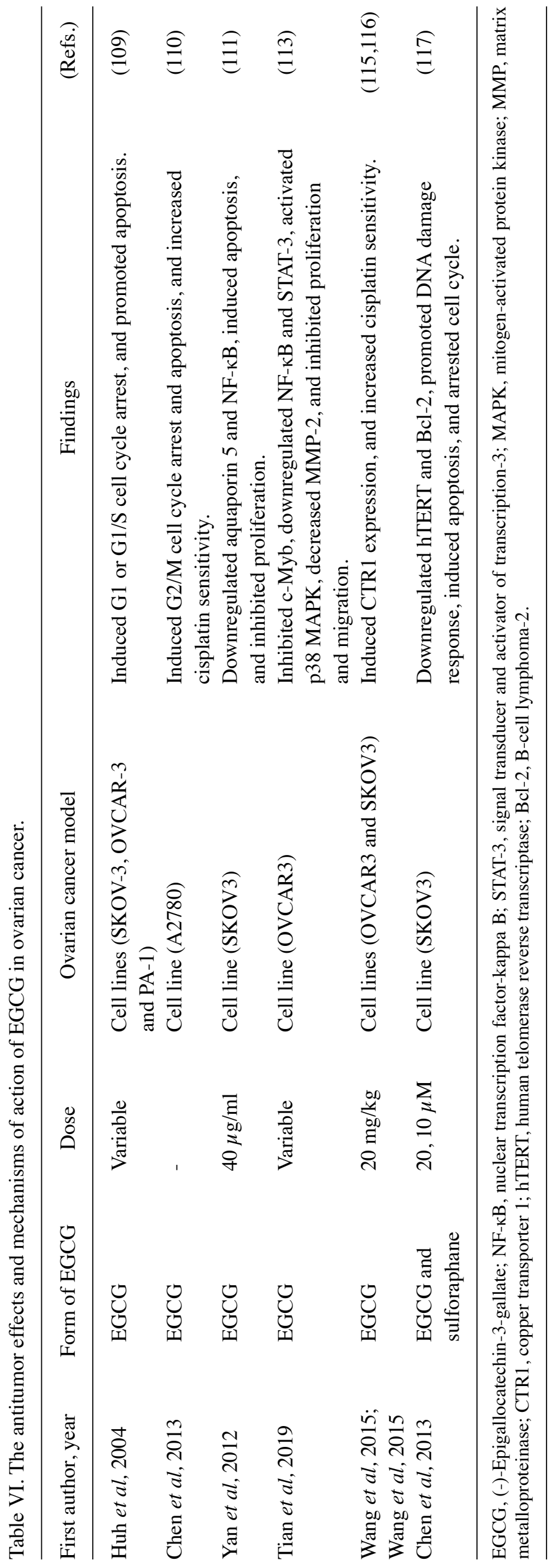


chemotherapy (103). In another study, berberine increased the expression of programmed cell death-4 (PDCD4) by inhibiting the expression of miR-21, a known molecule associated with ovarian cancer cisplatin resistance, thereby increasing apoptosis and enhancing cisplatin sensitivity (104). PDCD4, an important tumor suppressor, was revealed to be associated with the malignant phenotype of ovarian cancer (105). In addition, overexpression of miR-93 was involved in cisplatin resistance in ovarian cancer. Berberine increased the sensitivity of ovarian cancer cells to cisplatin through inhibiting the expression of $\mathrm{miR}-93$, thereby upregulating the expression of its target gene, PTEN (106). Hou et al (107), demonstrated that berberine induced apoptosis through increased DNA damage and suppressed homologous recombination, thereby increasing the sensitivity of ovarian cancer cells to PARP inhibitors (107).

\section{7. (-)-Epigallocatechin-3-gallate}

EGCG, a major component of green tea polyphenols, exhibited marked anti-angiogenic, antioxidant, anti-inflammatory and antitumor effects, among other beneficial pharmacological actions. Bioinformatic analysis has demonstrated that EGCG may affect a variety of signaling proteins in the cell cycle, including Jun, NF- $\mathrm{B}, \mathrm{Bcl}-2$ and MMPs, and also inhibits DNA replication (108). The antitumor effect and mechanisms of action of EGCG in ovarian cancer are listed in Table VI.

Effects on proliferation, apoptosis and autophagy. EGCG promoted the apoptosis of ovarian cancer cells by upregulating the levels of tumor suppressor gene, p53, and cell cycle inhibitor, p21WAF1. As a result, EGCG arrested ovarian cancer cells in the G1/S phase (109). Furthermore, EGCG induced the expression of p21 in cells, thereby promoting apoptosis and arresting these cells in the G2/M phase (110). EGCG downregulated the expression of aquaporin 5 and then downregulated NF- $\mathrm{NB}$, which subsequently induced apoptosis, and inhibited the proliferation and metastasis of SKOV3 cells (111). However, the role of berberine in autophagy in ovarian cancer remains unclear. In hepatocellular carcinoma, EGCG directly interacted with LC3-I protein and promoted the synthesis of LC3-II through a series of reactions, thereby increasing the autophagy activity of HepG2 cells (112).

Anti-metastatic activity. Overexpression of c-Myb in ovarian cancer tissues often leads to a poor prognosis, since c-Myb activates NF- $\mathrm{B}$ and the STAT-3 signaling pathway, which promotes tumor growth, invasion and chemotherapy resistance. Tian et al (113) evaluated numerous natural products and reported that EGCG significantly inhibited migration by downregulating the expression of c-Myb in ovarian cancer cells (113). Furthermore, EGCC inhibited the metastasis of ovarian cancer cells by inhibiting the phosphorylation of c-Jun and $\mathrm{NF}-\kappa \mathrm{B}$, resulting in the decreased expression of VEGF and the secretion of MMP-2 and MMP-9. Consequently, the adhesion of cancer cells to extracellular matrix proteins was weakened, and the supply of nutrients required for cell proliferation was reduced (108).

Sensitization. Previous studies have revealed the effects of EGCG combined with conventional chemotherapeutic drugs in ovarian cancer. Chan et al (114) reported that EGCG increased the cytotoxicity of cisplatin and enhanced its efficacy by 3-6 fold. Specifically, EGCG increased the oxidative stress of cisplatin-induced ovarian cancer cells through the generation of more reactive oxygen species to induce cell apoptosis (114). Copper transporter 1 (CTR1) of tumor cells may increase the uptake of cisplatin. However, cisplatin treatment rapidly promotes CTR 1 degradation, and decreased CTR1 is associated with cisplatin resistance. Wang et al $(115,116)$ reported that EGCG maintained the concentration of CTR1 in ovarian cancer cells, thereby increasing the cisplatin sensitivity $(115,116)$. Furthermore, in paclitaxel-resistant ovarian cancer cells, the combination of EGCG and sulforaphane treatment induced apoptosis and cell cycle arrest by damaging DNA and decreasing the expression of Bcl-2 and human telomerase reverse transcriptase (hTERT), the major catalytic subunit of telomerase, which was involved in cancer cell survival. The study suggested that EGCG may overcome paclitaxel resistance (117).

\section{Conclusions and perspectives}

Although conventional chemotherapy is known to produce positive initial effects in the majority of patients with ovarian cancer, cumulative toxicities and drug resistance often lead to the failure of conventional chemotherapy. Previous studies have revealed that numerous natural products are less toxic to healthy cells and inhibit tumor growth and progression to prevent malignant tumors. The present review summarizes the antitumor effects of natural products, primarily their role in the stimulation of autophagy, induction of apoptosis and cell cycle arrest, and the inhibition of cell proliferation and metastasis. Therefore, the administration of natural products (alone or in combination with other drugs) may be considered a useful treatment strategy in patients with ovarian cancer.

However, the mechanisms of action of natural products as therapeutic agents for ovarian cancer are relatively complex. The majority of previous studies have focused only on activity at the cellular level, and only few animal models have been developed. Further research is warranted to investigate the potential therapeutic efficacy of natural products in experimental animal models and randomized clinical trials. Accurate knowledge of the pharmacokinetic profile of each natural product is essential to evaluate the in vivo effects of the natural product.

The following issues require greater attention in future studies: i) The exact mechanisms that contribute toward the activity of natural products in ovarian cancer require further detailed investigation; ii) experimental animal model studies and randomized clinical trials should be performed to evaluate the therapeutic efficacy of natural products in ovarian cancer; iii) the effects of natural products combined with conventional chemotherapy, target therapy or immunotherapy need to be determined; and iv) novel methods should be developed to isolate and identify bioactive compounds from a variety of plants deemed suitable as anticancer agents.

\section{Acknowledgements}

Not applicable. 


\section{Funding}

The present study was supported by the National Natural Science Foundation of China (grant no. 81602303), the College Students' Innovative and Entrepreneurial Training Program of Hubei Province (grant no. 2019378), and the National College Students' Innovative and Entrepreneurial Training Program (grant no. 201910489014).

\section{Availability of data and materials}

Not applicable.

\section{Authors' contributions}

YBY conceived the topic and drafted the manuscript. YX revised the manuscript, and ensured that problems related to the accuracy or integrity of any part of the work were appropriately investigated and resolved. QT and JFZ collected the literature and revised the manuscript critically for important intellectual content. All authors read and approved the final manuscript.

\section{Ethics approval and consent to participate}

Not applicable.

\section{Patient consent for publication}

Not applicable.

\section{Competing interests}

The authors declare that they have no competing interests.

\section{References}

1. Bray F, Ferlay J, Soerjomataram I, Siegel RL, Torre LA and Jemal A: Global cancer statistics 2018: GLOBOCAN estimates of incidence and mortality worldwide for 36 cancers in 185 countries. CA Cancer J Clin 68: 394-424, 2018.

2. Duska LR and Kohn EC: The new classifications of ovarian fallopian tube, and primary peritoneal cancer and their clinical implications. Ann Oncol 28 (suppl_8): viii8-viii12, 2017.

3. Weidle UH, Birzele F, Kollmorgen G and Rueger R: Mechanisms and targets involved in dissemination of ovarian cancer. Cancer Genomics Proteomics 13: 407-423, 2016.

4. Tan DS, Agarwal R and Kaye SB: Mechanisms of transcoelomic metastasis in ovarian cancer. Lancet Oncol 7: 925-934, 2006

5. Cho KR and Shih Ie M: Ovarian cancer. Annu Rev Pathol 4 287-313, 2009.

6. Piccart MJ, Lamb H and Vermorken JB: Current and future potential roles of the platinum drugs in the treatment of ovarian cancer. Ann Oncol 12: 1195-1203, 2001.

7. Zhang SF, Wang XY, Fu ZQ, Peng QH, Zhang JY, Ye F, Fu YF, Zhou CY, Lu WG, Cheng XD, et al: TXNDC17 promotes paclitaxel resistance via inducing autophagy in ovarian cancer. Autophagy 11: 225-238, 2015.

8. Yang MF, Lou YL, Liu SS, Wang SS, Yin CH, Cheng XH and Huang OP: Capn4 overexpression indicates poor prognosis of ovarian cancer patients. J Cancer 9: 304-309, 2018.

9. De A, De A, Papasian C, Hentges S, Banerjee S, Haque I and Banerjee SK: Emblica officinalis extract induces autophagy and inhibits human ovarian cancer cell proliferation, angiogenesis, growth of mouse xenograft tumors. PLoS One 8 : e72748, 2013

10. Farzaei MH, Bahramsoltani R and Rahimi R: Phytochemicals as adjunctive with conventional anticancer therapies. Curr Pharm Des 22: 4201-4218, 2016.
11. Prasad S and Aggarwal BB: Turmeric, the Golden Spice: From traditional medicine to modern medicine. In Herbal Medicine: Biomolecular and Clinical Aspects (nd, Benzie IFF and Wachtel-Galor S, eds), Boca Raton (FL), 2011

12. Zhou H, Beevers CS and Huang S: The targets of curcumin. Curr Drug Targets 12: 332-347, 2011.

13. Dobbin ZC and Landen CN: The importance of the $\mathrm{PI} 3 \mathrm{~K} / \mathrm{AKT} / \mathrm{MTOR}$ pathway in the progression of ovarian cancer. Int J Mol Sci 14: 8213-8227, 2013.

14. Salakou S, Kardamakis D, Tsamandas AC, Zolota V Apostolakis E, Tzelepi V, Papathanasopoulos P, Bonikos DS, Papapetropoulos T, Petsas T, et al: Increased Bax/Bcl-2 ratio up-regulates caspase-3 and increases apoptosis in the thymus of patients with myasthenia gravis. In Vivo 21: 123-132, 2007.

15. Yu Z, Wan Y, Liu Y, Yang J, Li L and Zhang W: Curcumin induced apoptosis via PI3K/Akt-signalling pathways in SKOV3 cells. Pharma Biol 54: 2026-2032, 2016.

16. Watson JL, Greenshields A, Hill R, Hilchie A, Lee PW, Giacomantonio CA and Hoskin DW: Curcumin-induced apoptosis in ovarian carcinoma cells is p53-independent and involves p38 mitogen-activated protein kinase activation and downregulation of Bcl-2 and survivin expression and Akt signaling. Mol Carcinog 49: 13-24, 2010.

17. Bowman T, Garcia R, Turkson J and Jove R: STATs in oncogenesis. Oncogene 19: 2474-2488, 2000

18. Saydmohammed M, Joseph D and Syed V: Curcumin suppresses constitutive activation of STAT-3 by up-regulating protein inhibitor of activated STAT-3 (PIAS-3) in ovarian and endometrial cancer cells. J Cell Biochem 110: 447-456, 2010.

19. Seo JH, Jeong KJ, Oh WJ, Sul HJ, Sohn JS, Kim YK, Cho DY, Kang JK, Park CG and Lee HY: Lysophosphatidic acid induces STAT3 phosphorylation and ovarian cancer cell motility: Their inhibition by curcumin. Cancer Lett 288: 50-56, 2010.

20. Capiod T: Cell proliferation, calcium influx and calcium channels. Biochimie 93: 2075-2079, 2011.

21. Seo JA, Kim B, Dhanasekaran DN, Tsang BK and Song YS: Curcumin induces apoptosis by inhibiting Sarco/endoplasmic reticulum $\mathrm{Ca} 2+$ ATPase activity in ovarian cancer cells. Cancer Lett 371: 30-37, 2016

22. Kinose Y, Sawada K, Nakamura K and Kimura T: The role of microRNAs in ovarian cancer. Biomed Res Int 2014: 249393 , 2014

23. Du Z and Sha X: Demethoxycurcumin inhibited human epithelia ovarian cancer cells' growth via up-regulating miR-551a. Tumour Biol 39: 1010428317694302, 2017.

24. Meunier L, Puiffe ML, Le Page C, Filali-Mouhim A, Chevrette M, Tonin PN, Provencher DM and Mes-Masson AM: Effect of ovarian cancer ascites on cell migration and gene expression in an epithelial ovarian cancer in vitro model. Transl Oncol 3: 230-238, 2010.

25. Zhao J, Pan Y, Li X, Zhang X, Xue Y, Wang T, Zhao S and Hou Y: Dihydroartemisinin and curcumin synergistically induce apoptosis in SKOV3 cells via upregulation of MiR-124 targeting Midkine. Cell Physiol Biochem 43: 589-601, 2017.

26. Takei $Y$, Kadomatsu K, Matsuo S, Itoh H, Nakazawa K, Kubota $S$ and Muramatsu T: Antisense oligodeoxynucleotide targeted to Midkine, a heparin-binding growth factor, suppresses tumorigenicity of mouse rectal carcinoma cells. Cancer Res 61: 8486-8491, 2001

27. Zhao SF, Zhang X, Zhang XJ, Shi XQ, Yu ZJ and Kan QC: Induction of microRNA-9 mediates cytotoxicity of curcumin against SKOV3 ovarian cancer cells. Asian Pac J Cancer Prev 15: 3363-3368, 2014.

28. Zhan L, Zhang Y, Wang W, Song E, Fan Y, Li J and Wei B Autophagy as an emerging therapy target for ovarian carcinoma. Oncotarget 7: 83476-83487, 2016.

29. Boutouja F, Stiehm CM and Platta HW: mTOR: A cellular regulator interface in health and disease. Cells 8: 18, 2019.

30. Liu LD, Pang YX, Zhao XR, Li R, Jin CJ, Xue J, Dong RY and Liu PS: Curcumin induces apoptotic cell death and protective autophagy by inhibiting AKT/mTOR/p70S6K pathway in human ovarian cancer cells. Arch Gynecol Obstet 299: 1627-1639, 2019.

31. Qu W, Xiao J, Zhang H, Chen Q, Wang Z, Shi H, Gong L, Chen J, Liu Y, Cao R and Lv J: B19, a novel monocarbonyl analogue of curcumin, induces human ovarian cancer cell apoptosis via activation of endoplasmic reticulum stress and the autophagy signaling pathway. Int J Biol Sci 9: 766-777, 2013.

32. Kim I, Xu W and Reed JC: Cell death and endoplasmic reticulum stress: Disease relevance and therapeutic opportunities. Nat Rev Drug Discov 7: 1013-1030, 2008. 
33. Al-Alem L and Curry TE Jr: Ovarian cancer: Involvement of the matrix metalloproteinases. Reproduction 150: R55-R64, 2015.

34. Choe SR, Kim YN, Park CG, Cho KH, Cho DY and Lee HY: RCP induces FAK phosphorylation and ovarian cancer cell invasion with inhibition by curcumin. Exp Mol Med 50: 52 , 2018.

35. Lv J, Shao Q, Wang H, Shi H, Wang T, Gao W, Song B, Zheng G, Kong $\mathrm{B}$ and $\mathrm{Qu} \mathrm{X}$ : Effects and mechanisms of curcumin and basil polysaccharide on the invasion of SKOV3 cells and dendritic cells. Mol Med Rep 8: 1580-1586, 2013.

36. Pei H, Yang Y, Cui L, Yang J, Li X, Yang Y and Duan H: Bisdemethoxycurcumin inhibits ovarian cancer via reducing oxidative stress mediated MMPs expressions. Sci Rep 6: 28773, 2016.

37. Slack-Davis JK, Atkins KA, Harrer C, Hershey ED and Conaway M: Vascular cell adhesion molecule-1 is a regulator of ovarian cancer peritoneal metastasis. Cancer Res 69: 1469-1476, 2009.

38. Cornelison R, Llaneza DC and Landen CN: Emerging therapeutics to overcome chemoresistance in epithelial ovarian cancer: A Mini-review. Int J Mol Sci 18: 2171, 2017.

39. Yallapu MM, Maher DM, Sundram V, Bell MC, Jaggi M and Chauhan SC: Curcumin induces chemo/radio-sensitization in ovarian cancer cells and curcumin nanoparticles inhibit ovarian cancer cell growth. J Ovarian Res 3: 11, 2010.

40. Zhao MD, Li JQ, Chen FY, Dong W, Wen LJ, Fei WD, Zhang X, Yang PL, Zhang XM and Zheng CH: Co-Delivery of Curcumin and paclitaxel by 'Core-Shell' targeting Amphiphilic copolymer to reverse resistance in the treatment of ovarian cancer. Int J Nanomedicine 14: 9453-9467, 2019.

41. Zhang J, Liu J, Xu X and Li L: Curcumin suppresses cisplatin resistance development partly via modulating extracellular vesicle-mediated transfer of MEG3 and miR-214 in ovarian cancer. Cancer Chemother Pharmacol 79: 479-487, 2017.

42. Yang H, Kong W, He L, Zhao JJ, O'Donnell JD, Wang J, Wenham RM, Coppola D, Kruk PA, Nicosia SV and Cheng JQ: MicroRNA expression profiling in human ovarian cancer: miR-214 induces cell survival and cisplatin resistance by targeting PTEN. Cancer Res 68: 425-433, 2008

43. Daleprane JB and Abdalla DS: Emerging roles of propolis: Antioxidant, cardioprotective, and antiangiogenic actions. Evid Based Complement Alternat Med 2013: 175135, 2013.

44. Baur JA and Sinclair DA: Therapeutic potential of resveratrol: The in vivo evidence. Nat Rev Drug Discov 5: 493-506, 2006.

45. Liberti MV and Locasale JW: The Warburg effect: How does it benefit cancer cells? Trends Biochem Sci 41: 211-218, 2016

46. Vander Heiden MG, Cantley LC and Thompson CB Understanding the Warburg effect: The metabolic requirements of cell proliferation. Science 324: 1029-1033, 2009.

47. Pavlova NN and Thompson CB: The Emerging hallmarks of cancer metabolism. Cell Metab 23: 27-47, 2016.

48. Tan L, Wang W, He G, Kuick RD, Gossner G, Kueck AS, Wahl H, Opipari AW and Liu JR: Resveratrol inhibits ovarian tumor growth in an in vivo mouse model. Cancer 122: 722-729, 2016.

49. Gwak H, Kim S, Dhanasekaran DN and Song YS: Resveratrol triggers ER stress-mediated apoptosis by disrupting N-linked glycosylation of proteins in ovarian cancer cells. Cancer Lett 371: 347-353, 2016.

50. Majewska E and Szeliga M: AKT/GSK3 $\beta$ signaling in Glioblastoma. Neurochem Res 42: 918-924, 2017.

51. Tino AB, Chitcholtan K, Sykes PH and Garrill A: Resveratrol and acetyl-resveratrol modulate activity of VEGF and IL-8 in ovarian cancer cell aggregates via attenuation of the $N F-\kappa B$ protein. J Ovarian Res 9: 84, 2016.

52. Vergara D, Simeone P, Toraldo D, Del Boccio P, Vergaro V, Leporatti S, Pieragostino D, Tinelli A, De Domenico S Alberti S, et al: Resveratrol downregulates Akt/GSK and ERK signalling pathways in OVCAR-3 ovarian cancer cells. Mol Biosyst 8: 1078-1087, 2012.

53. Lang F, Qin Z, Li F, Zhang H, Fang Z and Hao E: Apoptotic cell death induced by resveratrol is partially mediated by the autophagy pathway in human ovarian cancer cells. PLoS One 10: e0129196, 2015

54. Kroemer G, Marino G and Levine B: Autophagy and the integrated stress response. Mol Cell 40: 280-293, 2010.

55. Kang R, Zeh HJ, Lotze MT and Tang D: The Beclin 1 network regulates autophagy and apoptosis. Cell Death Differ 18: 571-580, 2011.
56. Zhong LX, Zhang Y, Wu ML, Liu YN, Zhang P, Chen XY, Kong QY, Liu J and Li H: Resveratrol and STAT inhibitor enhance autophagy in ovarian cancer cells. Cell Death Discov 2: 15071,2016

57. Lu Z and Bast RC Jr: The tumor suppressor gene ARHI (DIRAS3) inhibits ovarian cancer cell migration through multiple mechanisms. Cell Adh Migr 7: 232-236, 2013.

58. Zhong LX, Nie JH, Liu J and Lin LZ: Correlation of ARHI upregulation with growth suppression and STAT3 inactivation in resveratrol-treated ovarian cancer cells. Cancer Biomark 21: 787-795, 2018

59. Ferraresi A, Phadngam S, Morani F, Galetto A, Alabiso O, Chiorino $\mathrm{G}$ and Isidoro C: Resveratrol inhibits IL-6-induced ovarian cancer cell migration through epigenetic up-regulation of autophagy. Mol Carcinog 56: 1164-1181, 2017.

60. Ferraresi A, Titone R, Follo C, Castiglioni A, Chiorino G, Dhanasekaran DN and Isidoro C: The protein restriction mimetic Resveratrol is an autophagy inducer stronger than amino acid starvation in ovarian cancer cells. Mol Carcinog 56: 2681-2691, 2017.

61. Mikula-Pietrasik J, Sosinska P and Ksiazek K: Resveratrol inhibits ovarian cancer cell adhesion to peritoneal mesothelium in vitro by modulating the production of alpha5 $\beta 1$ integrins and hyaluronic acid. Gynecol Oncol 134: 624-630, 2014.

62. Park SY, Jeong KJ, Lee J, Yoon DS, Choi WS, Kim YK, Han JW, Kim YM, Kim BK and Lee HY: Hypoxia enhances LPA-induced HIF-1alpha and VEGF expression: Their inhibition by resveratrol. Cancer Lett 258: 63-69, 2007.

63. Sopo M, Anttila M, Hamalainen K, Kivela A, Yla-Herttuala S, Kosma VM, Keski-Nisula L and Sallinen H: Expression profiles of VEGF-A, VEGF-D and VEGFR1 are higher in distant metastases than in matched primary high grade epithelial ovarian cancer. BMC Cancer 19: 584, 2019.

64. Wang H, Peng Y, Wang J, Gu A, Li Q, Mao D and Guo L: Effect of autophagy on the resveratrol-induced apoptosis of ovarian cancer SKOV3 cells. J Cell Biochem: Nov 18, 2018 (Epub ahead of print).

65. Nessa MU, Beale P, Chan C, Yu JQ and Huq F: Combinations of resveratrol, cisplatin and oxaliplatin applied to human ovarian cancer cells. Anticancer Res 32: 53-59, 2012.

66. Engelke LH, Hamacher A, Proksch P and Kassack MU: Ellagic acid and resveratrol prevent the development of cisplatin resistance in the epithelial ovarian cancer cell line A2780. J Cancer 7: 353-363, 2016.

67. Nag SA, Qin JJ, Wang W, Wang MH, Wang H and Zhang R: Ginsenosides as anticancer agents: In vitro and in vivo activities, Structure-activity relationships, and molecular mechanisms of action. Front Pharmacol 3: 25, 2012.

68. Ahuja A, Kim JH, Kim JH, Yi YS and Cho JY: Functional role of ginseng-derived compounds in cancer J Ginseng Res 42 248-254, 2018.

69. Li J, Liu T, Zhao L, Chen W, Hou H, Ye Z and Li X: Ginsenoside 20(S)Rg3 inhibits the Warburg effect through STAT3 pathways in ovarian cancer cells. Int J Oncol 46: 775-781, 2015.

70. Zheng X, Zhou Y, Chen W, Chen L, Lu J, He F, Li X and Zhao L: Ginsenoside 20(S)-Rg3 prevents PKM2-targeting miR-324-5p from $\mathrm{H} 19$ sponging to antagonize the Warburg effect in ovarian cancer cells. Cell Physiol Biochem 51: 1340-1353, 2018.

71. Lu J, Wang L, Chen W, Wang Y, Zhen S, Chen H, Cheng J, Zhou Y, Li X and Zhao L: miR-603 targeted hexokinase-2 to inhibit the malignancy of ovarian cancer cells. Arch Biochem Biophys 661: 1-9, 2019.

72. Bian S, Zhao Y, Li F, Lu S, Wang S, Bai X, Liu M, Zhao D, Wang J and Guo D: 20(S)-Ginsenoside Rg3 promotes HeLa cell apoptosis by regulating autophagy. Molecules 24: 3655, 2019.

73. Zheng X, Chen W, Hou H, Li J, Li H, Sun X, Zhao L and Li X Ginsenoside 20(S)-Rg3 induced autophagy to inhibit migration and invasion of ovarian cancer. Biomed Pharmacother 85. 620-626, 2017

74. Li J, Xi W, Li X, Sun H and Li Y: Advances in inhibition of protein-protein interactions targeting hypoxia-inducible factor-1 for cancer therapy. Bioorg Med Chem 27: 1145-1158, 2019.

75. Liu T, Zhao L, Zhang Y, Chen W, Liu D, Hou H, Ding L and $\mathrm{Li} \mathrm{X}$ : Ginsenoside $20(\mathrm{~S})-\mathrm{Rg} 3$ targets HIF-1 $\alpha$ to block hypoxia-induced epithelial-mesenchymal transition in ovarian cancer cells. PLoS One 9: e103887, 2014.

76. Liu T, Zhao L, Hou H, Ding L, Chen W and Li X: Ginsenoside 20 (S)-Rg3 suppresses ovarian cancer migration via hypoxia-inducible factor 1 alpha and nuclear factor-kappa B signals. Tumour Biol 39: 1010428317692225, 2017. 
77. Liu D, Liu T, Teng Y, Chen W, Zhao L and Li X: Ginsenoside Rb1 inhibits hypoxia-induced epithelial-mesenchymal transition in ovarian cancer cells by regulating microRNA-25. Exp Ther Med 14: 2895-2902, 2017.

78. Lengyel E: Ovarian cancer development and metastasis. Am J Pathol 177: 1053-1064, 2010.

79. Yun UJ, Lee JH, Koo KH, Ye SK, Kim SY, Lee CH and Kim YN Lipid raft modulation by $\mathrm{Rp} 1$ reverses multidrug resistance via inactivating MDR-1 and Src inhibition. Biochem Pharmacol 85 : 1441-1453, 2013.

80. Deng S, Wong CKC, Lai HC and Wong AST: Ginsenoside-Rb1 targets chemotherapy-resistant ovarian cancer stem cells via simultaneous inhibition of $\mathrm{Wnt} / \beta$-catenin signaling and epithelial-to-mesenchymal transition. Oncotarget 8: 25897-25914, 2017.

81. Metodiewa D, Jaiswal AK, Cenas N, Dickancaite E and Segura-Aguilar J: Quercetin may act as a cytotoxic prooxidant after its metabolic activation to semiquinone and quinoidal product. Free Radic Biol Med 26: 107-116, 1999.

82. Vargas AJ and Burd R: Hormesis and synergy: Pathways and mechanisms of quercetin in cancer prevention and management Nutr Rev 68: 418-428, 2010.

83. Hashemzaei M, Delarami Far A, Yari A, Heravi RE, Tabrizian K, Taghdisi SM, Sadegh SE, Tsarouhas K, Kouretas D, Tzanakakis G, et al: Anticancer and apoptosisinducing effects of quercetin in vitro and in vivo. Oncol Rep 38: 819-828, 2017.

84. Ren MX, Deng XH, Ai F, Yuan GY and Song HY: Effect of quercetin on the proliferation of the human ovarian cancer cell line SKOV-3 in vitro. Exp Ther Med 10: 579-583, 2015.

85. Zhou J, Gong J, Ding C and Chen G: Quercetin induces the apoptosis of human ovarian carcinoma cells by upregulating the expression of microRNA-145. Mol Med Rep 12: 3127-3131, 2015.

86. Teekaraman D, Elayapillai SP, Viswanathan MP and Jagadeesan A: Quercetin inhibits human metastatic ovarian cancer cell growth and modulates components of the intrinsic apoptotic pathway in PA-1cell line. Chem Biol Interact 300: 91-100, 2019.

87. Liu Y, Gong W, Yang ZY, Zhou XS, Gong C, Zhang TR, Wei X, $\mathrm{MaD}, \mathrm{YeF}$ and Gao QL: Quercetin induces protective autophagy and apoptosis through ER stress via the p-STAT3/Bcl-2 axis in ovarian cancer. Apoptosis 22: 544-557, 2017.

88. Yamauchi K, Afroze SH,Mitsunaga T,McCormick TC,Kuehl TJ, Zawieja DC and Uddin MN: 3,4,7-O-trimethylquercetin inhibits invasion and migration of ovarian cancer cells. Anticancer Res 37: 2823-2829, 2017

89. Wang Y, Han A, Chen E, Singh RK, Chichester CO, Moore RG, Singh AP and Vorsa N: The cranberry flavonoids PAC DP-9 and quercetin aglycone induce cytotoxicity and cell cycle arrest and increase cisplatin sensitivity in ovarian cancer cells. Int J Oncol 46: 1924-1934, 2015.

90. Yang Z, Liu Y, Liao J, Gong C, Sun C, Zhou X, Wei X, Zhang T, Gao Q, Ma D and Chen G: Quercetin induces endoplasmic reticulum stress to enhance cDDP cytotoxicity in ovarian cancer: Involvement of STAT3 signaling. FEBS J 282: 1111-1125, 2015

91. Gong C, Yang Z, Zhang L, Wang Y, Gong W and Liu Y: Quercetin suppresses DNA double-strand break repair and enhances the radiosensitivity of human ovarian cancer cells via $\mathrm{p} 53$-dependent endoplasmic reticulum stress pathway. Onco Targets Ther 11: 17-27, 2018.

92. Yi L, Zongyuan Y, Cheng G, Lingyun Z, Guilian Y and Wei G: Quercetin enhances apoptotic effect of tumor necrosis factor-related apoptosis-inducing ligand (TRAIL) in ovarian cancer cells through reactive oxygen species (ROS) mediated CCAAT enhancer-binding protein homologous protein (CHOP)-death receptor 5 pathway. Cancer Sci 105: 520-527, 2014.

93. Ouellet V, Le Page C, Madore J, Guyot MC, Barres V, Lussier C, Tonin PN, Provencher DM and Mes-Masson AM: An apoptotic molecular network identified by microarray: On the TRAIL to new insights in epithelial ovarian cancer. Cancer 110: 297-308, 2007.

94. Tillhon M, Guaman Ortiz LM, Lombardi P and Scovassi AI Berberine: New perspectives for old remedies. Biochem Pharmacol 84: 1260-1267, 2012.

95. Sun Y, Xun K, Wang Y and Chen X: A systematic review of the anticancer properties of berberine, a natural product from Chinese herbs. Anticancer Drugs 20: 757-769, 2009.

96. Liu L, Fan J, Ai G, Liu J, Luo N, Li C and Cheng Z: Berberine in combination with cisplatin induces necroptosis and apoptosis in ovarian cancer cells. Biol Res 52: 37, 2019.

97. Nakanishi M and Rosenberg DW: Multifaceted roles of PGE2 in inflammation and cancer. Semin Immunopathol 35: 123-137, 2013

98. Zhao Y, Cui L, Pan Y, Shao D, Zheng X,Zhang F,Zhang H,He K and Chen L: Berberine inhibits the chemotherapy-induced repopulation by suppressing the arachidonic acid metabolic pathway and phosphorylation of FAK in ovarian cancer. Cell Prolif 50: e12393, 2017.

99. Zhi D, Zhou K, Yu D, Fan X, Zhang J, Li X and Dong M: hERG1 is involved in the pathophysiological process and inhibited by berberine in SKOV3 cells. Oncol Lett 17: 5653-5661, 2019.

100. Zhang Q, Wang X, Cao S, Sun Y, He X, Jiang B, Yu Y, Duan J, Qiu F and Kang N: Berberine represses human gastric cancer cell grow th in vitro and in vivo by inducing cytostatic autophagy via inhibition of MAPK/mTOR/p70S6K and Akt signaling pathways. Biomed Pharmacother 128: 110245, 2020.

101. Hu Q, Li L, Zou X, Xu L and Yi P: Berberine attenuated proliferation, invasion and migration by targeting the AMPK/HNF4 $\alpha /$ WNT5A pathway in gastric carcinoma. Front Pharmacol 9: 1150, 2018.

102. Wang Y and Zhang S: Berberine suppresses growth and metastasis of endometrial cancer cells via miR-101/COX-2. Biomed Pharmacother 103: 1287-1293, 2018.

103. Marverti G, Ligabue A, Lombardi P, Ferrari S, Monti MG, Frassineti C and Costi MP: Modulation of the expression of folate cycle enzymes and polyamine metabolism by berberine in cisplatin-sensitive and -resistant human ovarian cancer cells. Int J Oncol 43: 1269-1280, 2013.

104. Liu S, Fang Y, Shen H, Xu W and Li H: Berberine sensitizes ovarian cancer cells to cisplatin through miR-21/PDCD4 axis. Acta Biochim Biophys Sin (Shanghai) 45: 756-762, 2013.

105. Wei ZT, Zhang X, Wang XY, Gao F, Zhou CJ, Zhu FL, Wang Q, Gao Q, Ma CH, Sun WS, et al: PDCD4 inhibits the malignant phenotype of ovarian cancer cells. Cancer Sci 100: 1408-1413, 2009.

106. Chen Q, Qin R, Fang Y and Li H: Berberine sensitizes human ovarian cancer cells to cisplatin through miR-93/PTEN/Akt signaling pathway. Cell Physiol Biochem 36: 956-965, 2015.

107. Hou D, Xu G, Zhang C, Li B, Qin J, Hao X, Liu Q, Zhang X, Liu J, Wei J, et al: Berberine induces oxidative DNA damage and impairs homologous recombination repair in ovarian cancer cells to confer increased sensitivity to PARP inhibition. Cell Death Dis 8: e3070, 2017.

108. Xinqiang S, Mu Z, Lei C and Mun LY: Bioinformatics analysis on molecular mechanism of green tea compound epigallocatechin-3-gallate against ovarian cancer. Clin Transl Sci 10: 302-307, 2017

109. Huh SW, Bae SM, Kim YW, Lee JM, Namkoong SE, Lee IP, Kim SH, Kim CK and Ahn WS: Anticancer effects of (-)-epigallocatechin-3-gallate on ovarian carcinoma cell lines. Gynecol Oncol 94: 760-768, 2004.

110. Chen H, Landen CN, Li Y, Alvarez RD and Tollefsbol TO: Enhancement of Cisplatin-mediated apoptosis in ovarian cancer cells through potentiating G2/M Arrest and p21 upregulation by combinatorial epigallocatechin gallate and sulforaphane. J Oncol 2013: 872957, 2013

111. Yan C, Yang J, Shen L and Chen X: Inhibitory effect of Epigallocatechin gallate on ovarian cancer cell proliferation associated with aquaporin 5 expression. Arch Gynecol Obstet 285: 459-467, 2012

112. Zhao L, Liu S, Xu J, Li W, Duan G, Wang H, Yang H, Yang Z and Zhou R: A new molecular mechanism underlying the EGCG-mediated autophagic modulation of AFP in HepG2 cells. Cell Death Dis 8: e3160, 2017.

113. Tian M, Tian D, Qiao X, Li J and Zhang L: Modulation of Myb-induced NF-kB-STAT3 signaling and resulting cisplatin resistance in ovarian cancer by dietary factors. J Cell Physiol 234: 21126-21134, 2019.

114. Chan MM, Soprano KJ, Weinstein K and Fong D: Epigallocatechin-3-gallate delivers hydrogen peroxide to induce death of ovarian cancer cells and enhances their cisplatin susceptibility. J Cell Physiol 207: 389-396, 2006.

115. Wang X, Jiang P, Wang P, Yang CS, Wang X and Feng Q: EGCG enhances cisplatin sensitivity by regulating expression of the copper and cisplatin influx transporter CTR 1 in ovary cancer. PLoS One 10: e0125402, 2015.

116. Wang $X$, Jiang $P$, Wang $P$, Yang CS, Wang $X$ and Feng Q Correction: EGCG enhances cisplatin sensitivity by regulating expression of the copper and cisplatin influx transporter CTR 1 in ovary cancer. PLoS One 10: e0132086, 2015.

117. Chen H, Landen CN, Li Y, Alvarez RD and Tollefsbol TO: Epigallocatechin gallate and sulforaphane combination treatment induce apoptosis in paclitaxel-resistant ovarian cancer cells through hTERT and Bcl-2 down-regulation. Exp Cell Res 319: 697-706, 2013. 